\title{
A Tecnologia Social e sua Contribuição para a Educação em Ciências
}

\section{Social Technology and its Contribution to Science Education}

\author{
Miguel Guilhermino de Archanjo Junior \\ Simoni Tormohlen Gehlen \\ Brasil \\ Brasil
}

\begin{abstract}
A Tecnologia Social é caracterizada como um produto, técnica e/ou metodologia reaplicável e desenvolvida com a participação da comunidade para a resolução de problemas sociais/socioambientais. Nesse sentido, investiga-se a apropriação de alguns pressupostos teórico-metodológicos da Tecnologia Social por parte dos sujeitos da comunidade local e escolar, que participaram da seleção e implementação de uma Tecnologia Social, em busca da superação de uma demanda local na comunidade do Iguape, no município Ilhéus, BA. Metodologicamente, a pesquisa foi organizada em duas etapas: a) reunião com os moradores do bairro, para discutir a demanda socioambiental local e selecionar uma Tecnologia Social; b) implementação de uma Fossa Séptica Ecológica na comunidade em colaboração com os moradores. As informações foram obtidas por meio de videogravações realizadas durante a reunião e a implementação da fossa e entrevistas semiestruradas com os moradores que participaram de todo o processo. A análise se deu por meio da Análise Textual Discursiva tendo como referência duas categorias a priori: i) coaprendizagem e reaplicação; e ii) processos de tomada de decisões e autonomia. Dentre os resultados, constatou-se que a construção da fossa possibilitou a integração entre o conhecimento popular e os científicos, propiciando a reaplicação da TS na comunidade local, além da transformação sociotécnica, que se deu por meio de um processo colaborativo. Além disso, evidenciou-se que a TS tem um significativo potencial para contribuir na seleção de conteúdos e conhecimentos para o currículo escolar, como os da área de Ciências Naturais.
\end{abstract}

Palavras-chave: Tecnologia Social; Investigação Temática; Demandas Sociais; Paulo Freire.

Social Technology is characterized as a product, technique and/or methodology that can be reapplied and is developed with the participation of the community to solve social/ socio-environmental problems. In this sense, we investigate the appropriation of some theoretical and methodological assumptions of Social Technology by the subjects of the local and school community, who participated in the selection and implementation of a Social Technology, in search of overcoming a local demand in the Iguape community, in the municipality of Ilhéus, in the state of Bahia in Brazil. Methodologically, the research 
was organized in two stages: a) meeting with the residents of the Iguape neighborhood to discuss the local socio-environmental demand and select a Social Technology; b) construction of an Ecological Septic Tank in the community in collaboration with residents. Data were collected through video recordings made during the meetings and tank implementation; also through semi-structured interviews with the residents who participated in the entire process. The analysis was performed through Discursive Textual Analysis, having as reference two categories a priori: i) co-learning and reapplication; and ii) decision-making and autonomy processes. Among the results, we found that the construction of the Ecological Septic Tank made possible the integration between popular and scientific knowledge, enabling the reapplication of Social Technology in the local community, in addition to the socio-technical transformation, which took place through a collaborative process. Finally, we point out that Social Technology has a significant potential to contribute in the selection of contents and knowledge for the school curriculum, involving contents such as from the Natural Sciences field.

Keywords: Social Technology; Thematic Research; Social and Environmental Problems; Paulo Freire.

\section{Introdução}

Historicamente, houve diferentes formas de conceber e desenvolver tecnologias, uma tornou-se hegemônica e outras, alternativas, a exemplo da Tecnologia Social (TS) que consiste em um desenvolvimento participativo com a comunidade, a fim de buscar a resolução de problemas sociais locais, bem como o compromisso com a transformação da sua realidade, a sustentabilidade, a inclusão social e a democratização do saber, os quais são balizados por meio dos fundamentos que a constitui, quais sejam: autonomia, tomada de decisões, coaprendizagem e reaplicação (Roso, 2017). Esses fundamentos também são compreendidos como os pressupostos teóricos que permeiam a TS e explicitam suas principais características. Nesse sentido, Dagnino, Brandão e Novaes (2004) afirmam que a TS pode ser definida como: produtos, técnicas e/ou metodologias reaplicáveis e desenvolvidas com a participação da população local. Além disso, essa tecnologia pode contribuir para a resolução de problemas sociais ou socioambientais, tornando-se fundamental para a superação dos problemas concretos da comunidade investigada. Roso (2017) sinaliza que a TS necessita ser planejada e implementada na interação com a comunidade em que se pretende desenvolvê-la, bem como no contexto educacional local.

Alguns pesquisadores têm discutido a TS como uma maneira de contribuir com a equidade social, qualidade de vida e sustentabilidade (Costa, 2013; Dagnino et al., 2004; Dagnino, 2011; 2014; 2015; Lassance Jr., \& Pedreira, 2004; Roso, 2017). Essa tecnologia apresenta aspectos importantes no sentido de minimizar ou superar as contradições sociais que afetam a sociedade, como o protagonismo social, a interação social, trabalhos colaborativos e coprodução, como aponta Dagnino (2011). Para Lassance Jr. e Pedreira 
(2004), a TS pode ser desenvolvida coletivamente, organizada de maneira formal ou informal, mas sempre voltada para promoção da saúde, revitalização de espaços públicos ociosos, atividades de lazer ou resolução de conflitos sociais e socioambientais, ou seja, para a superação de uma demanda social que pode contribuir no processo de humanização e protagonismo social.

É importante que a TS seja realmente um meio para a superação das demandas da comunidade, uma vez que o problema necessita ser selecionado, discutido e planejado no seu contexto. Para Roso (2017), uma das formas de identificar a TS pode ser por meio da Investigação Temática, na obtenção de Temas Geradores, que além de contribuir para a reorganização de currículos pedagógicos, pode tornar-se uma estratégia teóricometodológica fundamental para identificar demandas sociais (Freire, 1987). Auler e Delizoicov (2015) discutem que essas demandas sociais estão localizadas no espaçotempo e que há necessidade de se considerar suas especificidades no espaço geográfico e no período histórico que ocorrem e não compreendê-las como demandas universais.

No contexto de suas relações com a Educação em Ciências, Roso (2017) - ao realizar uma revisão nos Anais do Encontro Nacional de Pesquisa em Educação em Ciências (ENPEC), Simpósio Nacional de Ciência, Tecnologia e Sociedade (TECSOC) e Jornadas Latino-americanas de Estudos Sociais da Ciência e Tecnologia (ESOCITE), no ano de 2017 - constata a ausência de trabalhos que envolvem a TS, o que sinaliza a incipiência de pesquisas nessa perspectiva. Para o autor, esse resultado evidencia a necessidade da TS ser considerada em processos formativos/educativos nessa respectiva área, uma vez que os problemas sociais têm-se tornado cada dia mais presentes em nossa sociedade.

Diante disso, entende-se que há a necessidade de uma proposta na Educação em Ciências na perspectiva da TS, que viabilize atividades pedagógicas societárias tendo como foco a abordagem de conhecimentos e práticas que propiciem uma intervenção crítica na realidade por meio do desenvolvimento da autonomia, tomada de decisões, coaprendizagem e reaplicação (Roso, 2017). Nesse sentido, colocam-se os seguintes questionamentos: De que forma os fundamentos da Tecnologia Social podem contribuir para superação de um problema social/socioambiental local? E como essa proposta pedagógica societária poderá potencializar a elaboração de currículos para Educação em Ciências a partir da realidade dos sujeitos?

Tendo em vista esses aspectos, desenvolveu-se um processo formativo de professores de uma escola de Educação Infantil, no município de Ilhéus-BA, em que realizou-se uma ação em conjunto com a comunidade escolar, considerando a forma de trabalho no âmbito da TS. No contexto dessa atividade, investigou-se a apropriação dos seguintes fundamentos da TS: autonomia, tomada de decisões, coaprendizagem e reaplicação, por parte dos sujeitos da comunidade local/escolar, bem como apresentouse algumas possibilidades para a Educação em Ciências. Os sujeitos em questão, referem-se aos moradores da comunidade do Iguape, na qual está inserida a Escola Padre Giuseppe Bonomi, que participaram do processo de seleção e implementação de 
uma TS, em busca da superação de uma demanda local. Essa investigação pode sinalizar contribuições para a elaboração do currículo escolar da Escola Padre Giuseppe Bonomi, em especial, quanto à inserção de conteúdos e conhecimentos vinculados à Educação em Ciências.

\section{A Tecnologia Social e seu papel na Educação em Ciências}

A TS surgiu em detrimento dos outros modelos de tecnologias que não foram bem sucedidos no âmbito econômico e tecnológico (Dagnino et al., 2004). O movimento da TS tem sido discutido de forma ponderada às necessidades de suas demandas, buscando sempre evitar os erros cometidos pelos modelos anteriores (a compreensão que a tecnologia era neutra, agenda de pesquisa, ausência de compromisso social, etc.), procurando aperfeiçoar suas empregabilidades e fundamentando as suas discussões na perspectiva de uma proposta societária. Outro aspecto relevante que Dagnino et al. (2004) discutem é a necessidade da adequação sociotécnica do modelo de tecnologia hegemônico para a realidade da população que está à margem da sociedade, proporcionando uma qualidade de vida no âmbito de sua realidade. Para isso, os autores afirmam que a TS é fundamental para superar alguns valores que legitimaram e balizaram o movimento da Tecnologia Apropriada (TA), como: a participação direta dos sujeitos no processo de desenvolvimento e implementação da TS, na tentativa de desenvolver nos atores sociais os seus fundamentos, como o processo de coaprendizagem e autonomia. Roso (2017) também sinaliza que os fundamentos que embasam a TS viabilizam a interação entre os conhecimentos populares e científicos, o que corrobora para a coletividade e democratização do saber. Sendo assim, o autor afirma que os fundamentos da TS confrontam o modelo hegemônico de educação da sociedade atual:

Diferente da TC (Tecnologia Convencional), a TS objetiva o desenvolvimento local de tecnologia de acordo com necessidades, objetivos, interesses de grupos sociais que, em geral, estão à margem da lógica de mercado. TS configura-se, portanto, como uma forma não tradicional de compreender as relações CTS, deslocando, sobretudo, a origem da demanda por soluções técnicas, da lógica de mercado para a sociedade, para populações que passam a ser consideradas grupos sociais relevantes. (Roso, 2017, p. 19).

A TS pode contribuir de forma efetiva na formação de sujeitos críticos e transformadores, tendo em vista a construção de conhecimentos e práticas capazes de propiciar nos sujeitos uma intervenção crítica no contexto social que estão inseridos (Dagnino, 2011). Para tanto, Roso (2017) explica que a transformação local requer uma postura crítica dos atores sociais, assim como uma atuação efetiva e consciente das relações existentes entre suas realidades e a sociedade que os cercam. Diante das abordagens sobre a TS, alguns autores brasileiros (Dagnino, 2004; 2011; 2015, \& Roso, 2017) têm discutido a sua definição, apontando para uma compreensão mais consensual atualmente, mas que ainda está em construção no Brasil. Além do mais, os autores apontam que essa tecnologia tornou-se uma alternativa fundamental na transformação da cultura silenciada pela tecnologia hegemônica, presente no processo sócio-histórico 
da população em situação de vulnerabilidade social.

A autonomia é compreendida como um fundamento que compõe a TS, visto que viabiliza a tomada de decisões e a autogestão, mediante uma proposta pedagógica societária, tanto do ponto de vista dos sujeitos, quanto do processo (Marques, 2010). Para Dagnino (2011), a participação dos sujeitos em todo o processo de desenvolvimento da TS é fundamental na sua ressignificação, de forma a potencializar o papel de agente transformador de sua realidade, bem como apropriar-se de outros fundamentos que constituem a TS, como a coaprendizagem. O autor afirma que esses elementos da TS, promovem a interação, coletividade e a busca constante pela construção da cidadania e pela organização de uma sociedade mais inclusiva.

Para Samagaia (2016), a autonomia é construída mediante a interação do sujeito com os grupos sociais e acadêmicos, possibilitando a tomada de decisões de acordo com as diversas concepções. A autonomia também pode ser concebida a partir da aquisição de novos conhecimentos ou ampliação do saber que o sujeito possui, permitindo criar condições para que esse se posicione com responsabilidade frente às demandas sociais que emergem em seu contexto (Freire, 1987). Freire (1987) compreende a autonomia a partir da criticidade, ou seja, quando o sujeito desenvolve o nível de consciência máxima possível, possibilitando uma visão de mundo crítica e transformadora da sua realidade. Nesse sentido, Roso (2017) chama a atenção para os fundamentos da TS no contexto formativo/educativo e aponta que:

No âmbito da TS a formação/educação é mais ampla: usuários e sociedade, direta ou indiretamente relacionada com os "produtos", são fundamentais no processo de desenvolvimento no sentido que eles também se educam ao educarem os técnicos envolvidos a partir das diferentes visões de grupo. Ainda, as decisões tomadas não são centralizadas em determinadas pessoas e/ou grupo, mas, sim, tomadas pelo coletivo tendo como horizonte processos cada vez mais democráticos. (Roso, 2017, p. 85).

A coaprendizagem e a autonomia - como fundamentos da TS -, no âmbito de um processo formativo/educativo, possibilitam compreensões diferentes sobre o mesmo objeto, viabilizando aos participantes a construção do saber mútuo. Diante disso, destaca-se o papel da coaprendizagem para o desenvolvimento de uma proposta pedagógica societária, a qual promove nos sujeitos uma formação coletiva, bem como a integração de novos conhecimentos, ou seja, a democratização do saber (Roso, 2017). A coaprendizagem também pode contribuir para balizar ações na perspectiva da TS com a finalidade de sanar ou minimizar um problema social e promover trabalhos coletivos de forma colaborativa (Lassance Jr., \& Pedreira, 2004).

A perspectiva da coaprendizagem se constitui no processo de interação entre os conhecimentos populares e científicos - na medida em que o técnico e os moradores (atores sociais), necessariamente, trabalham em conjunto na construção mútua de uma TS, levando em consideração as adequações sociotécnicas, a fim de sua reaplicação (Samagaia, 2016). Além disso, a intervenção crítica por meio da Investigação Temática (Freire, 1987) em perspectiva da TS, potencializa a elaboração de propostas didáticas 
voltadas para a Educação em Ciências, como foi sinalizado por Roso (2017), na tentativa de discutir problemas concretos presentes na comunidade escolar, tendo como finalidade promover uma educação humanizadora no contexto dos sujeitos a partir de conteúdos da área do ensino de ciências, presentes na realidade concreta dos seus participantes.

Roso (2017) destaca a importância da TS na construção de um currículo didático potencialmente crítico e contextualizado, que possa de fato atender as problemáticas locais atuais. Além disso, o autor explicita que a construção de um currículo escolar também pode contribuir para um modelo de educação capaz de promover uma sociedade mais societária e consciente das problemáticas que estão presentes em seu contexto social, bem como a produção de tecnologias e elaboração propostas pedagógicas no âmbito das Ciências Naturais, em que o objeto de estudo esteja relacionado com a realidade local. Roso (2017) também menciona que há uma necessidade de se trabalhar a Investigação Temática (Freire, 1987), com vista à possibilidade de identificar contradições sociais/ socioambientais presentes na comunidade investigada, como alternativa de superação das problemáticas encontradas no contexto em que o sujeito estiver imerso. Isso porque “a realização da Investigação Temática além de sinalizar parâmetros para a construção e execução de novos currículos poderiam ser um importante processo de identificação de demandas locais, necessidades reais da sociedade local" (Roso, 2017, p. 25).

De acordo com a proposta de Roso (2017), os elementos presentes na Investigação Temática podem auxiliar na identificação das problemáticas da realidade do sujeito, objetivando que a TS seja uma possibilidade de superação dos problemas concretos da comunidade e propicie o protagonismo social em seus participantes. $\mathrm{O}$ autor também sinaliza que estas demandas sociais sejam trabalhadas no âmbito educacional, para promover uma formação crítica e transformadora nos sujeitos. Para melhor compreender alguns aspectos dos fundamentos que permeiam a TS, organizou-se na Figura 1 um esquema, representando-os em duas etapas, quais sejam: i) Princípios e ii) Ações.

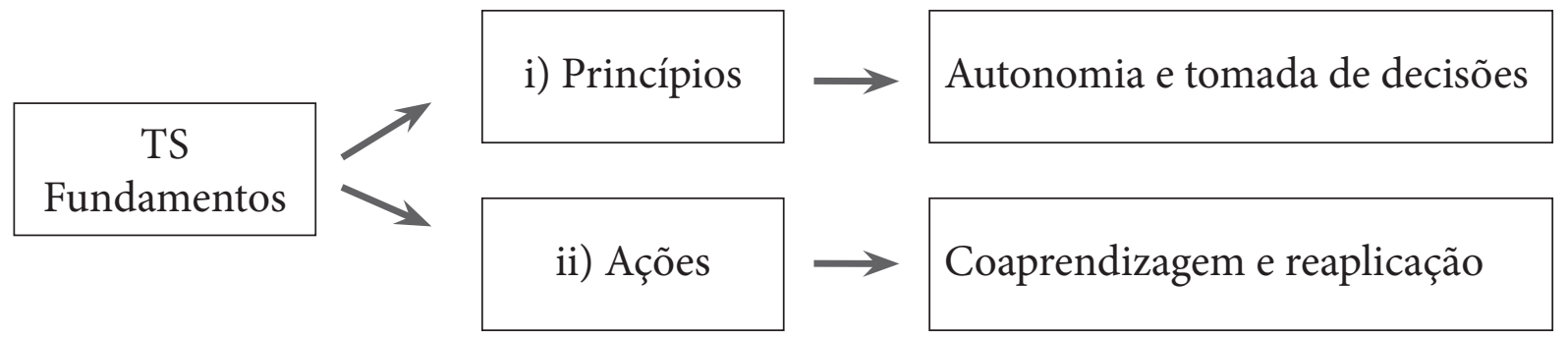

Figura 1. Organização dos fundamentos da TS

i) Princípios - são constituídos pela autonomia e tomada de decisões, tornandose a gênese para o encaminhamento de uma proposta crítico-transformadora no âmbito educacional. Esses princípios podem potencializar a criticidade do sujeito diante dos problemas sociais presentes em sua realidade. Nesse sentido, a participação do sujeito no desenvolvimento de uma proposta societária, possibilitará uma atuação ativa, contribuindo para a democratização do saber, bem como para o protagonismo social (Roso, 2017). Esses princípios (autonomia e tomada de decisões) podem emergir a 
partir da dialogicidade, problematização e conscientização, estando em coerência com o processo de Investigação Temática (Freire, 1987), que tem em vista contrapor um modelo educacional hegemônico e alienante e promover uma educação humanizadora.

No esquema da Figura 1, a seta que parte dos Princípios em direção às Ações indica que o sujeito participante de uma proposta pedagógica societária precisa se apropriar primeiro dos conhecimentos presentes nos Princípios, a fim de despertar a sua criticidade e compreensão dos problemas da sua realidade em sua totalidade, e assim, possa discutir e efetivar de forma colaborativa possíveis ações com o propósito de transformá-la. Dessa forma, faz-se necessário que os Princípios precedam as Ações para evitar que a TS seja desenvolvida em uma concepção neutra ou balizada pelos valores hegemônicos (valores capitalistas), mas, que essa tecnologia leve em consideração no processo de implementação os valores culturais, socioeconômicos, sócio-históricos e socioambientais, ou seja, as especificidades da realidade local (Dagnino, 2014).

ii) Ações - representam a coaprendizagem e a reaplicação e estão relacionadas à implementação de uma proposta crítico-transformadora no contexto de uma comunidade escolar e/ou no seu em torno. A coaprendizagem e a reaplicação são fundamentos constituintes dessa etapa e, balizadas por ações colaborativas, dialógicas e emancipadora, com o propósito de promover na comunidade escolar e/ ou local a democratização do saber e a transformação social na localidade, a partir da aprendizagem mútua dos sujeitos participantes (Roso, 2017). A dialogicidade entre os sujeitos participantes é fundamental para efetivação dessa etapa, uma vez que essa pode ser direcionada pelo processo de Investigação Temática (Freire, 1987), na tentativa de promover um processo formativo/educativo emancipador, potencializando a apropriação do conhecimento novo e contribuindo para a intervenção crítica na realidade do sujeito. Os conhecimentos adquiridos desse processo formativo/educativo emancipador constituem a coaprendizagem, tornando-se um fundamento essencial para a reaplicação de uma TS no contexto social, local e/ou escolar, a fim de superar as demandas presentes nessa comunidade (Roso, 2017). Em síntese, as demandas identificadas na localidade são passíveis de serem abordadas no contexto escolar, sinalizando assim, possíveis elementos (conteúdos) para a elaboração de um currículo emancipador em diversas áreas do conhecimento científico, inclusive, na área de Educação e Ciências (Silva, 2004).

$\mathrm{Na}$ proposta de uma educação emancipadora, Freire (1987) defende que o processo da Investigação Temática (IT), para a obtenção de Temas Geradores, constituise na problematização e dialogicidade, com a finalidade de estabelecer mecanismos que possibilitem a superação do sujeito que se encontra oprimido à margem da sociedade. Esta proposta de educação está em consonância com as características da TS, isso porque, como destaca Dagnino (2011), essa tecnologia apresenta indicativos capazes de promover uma formação cidadã do sujeito diante dos problemas sociais, presentes em sua realidade, bem como torná-lo um agente transformador da sua história.

Tendo em vista uma proposta pedagógica humanizadora, que pode contribuir para a formação crítica do sujeito, vale destacar que Freire (1987) explicita que a 
formação cidadã pode ser promovida por meio do processo de IT, que é constituída por estratégias teórico-metodológicas que visam abordar a realidade dos educandos no contexto da educação, sem perder o caráter dialógico e problematizador. O processo da IT para obtenção de Temas Geradores foi sistematizado no capítulo três da obra Pedagogia do Oprimido (Freire, 1987), para a educação não formal em quatro etapas, quais sejam: 1) Levantamento Preliminar: reconhecimento local da comunidade; 2) Codificação: análise e escolha de contradições sociais, caracterizadas de situações-limite, vivenciadas pelos envolvidos; 3) Descodificação: legitimação dessas situações-limite e sua sintetização em Temas Geradores; 4) Redução Temática: seleção do conteúdo programático para compreender o Tema Gerador. Essa dinâmica, posteriormente, foi adaptada por Delizoicov $(1983 ; 1991)$ e Delizoicov, Angotti e Pernambuco (2011) para a educação escolar. Nesse processo, destacam-se os Três Momentos Pedagógicos (3MP), os Conceitos Unificadores e a quinta etapa da Investigação Temática, que corresponde à implementação da atividade na sala de aula, denominada de 5) Desenvolvimento em Sala Aula: implementação de atividades em sala de aula.

Assunção (2019) investigou contribuições da IT para a superação das contradições sociais e as percepções dos sujeitos sobre os problemas vivenciados na realidade do Iguape e identificou algumas situações-limite ${ }^{1}$, principalmente, relacionados à falta de saneamento básico, contaminação do solo e da água, poluição dos manguezais (despejos dos dejetos domésticos no manguezal), já que os dejetos produzidos pela pela população local são destinados de forma irregular a esses ambientes, impactando negativamente nos ecossistemas marinhos. Dentre essas demandas sociais da comunidade investigada, destacam-se aquelas passíveis de serem superadas por meio de uma TS, quais sejam: coleta seletiva, plantio, compostagem (construção de composteira), saneamento básico, esgotos, fossas, tratamento da água, lazer, pesca predatória, cultura de subsistência e turismo.

Essas problemáticas também podem contribuir para a elaboração de um currículo escolar local, contemplando diversas áreas do conhecimento, a exemplo dos conteúdos e conceitos abordados em Ciências Naturais. Nessa perspectiva, Assunção (2019) elaborou em conjunto com as professoras da Escola Padre Giuseppe Bonomi, um planejamento didático-pedagógico para ser desenvolvido com as crianças da Educação Infantil, seguindo aspectos relacionados às situações-limite, vivenciadas pela população, relacionadas a diversos problemas, tendo como foco o Brincar (Barbosa, 2020). Na presente pesquisa, deu-se continuidade às atividades realizadas por Assunção (2019) com a comunidade investigada, tendo como foco o envolvimento dos moradores na compreensão das demandas sociais - que no caso foi a questão do despejo dos dejetos domésticos no mangue -, e na busca de alternativas para superá-las por meio de uma proposta pedagógica societária, ou seja, a partir da implementação de uma TS, conforme será explicitado nos próximos itens.

1 Entende-se por situações-limite as compreensões dos sujeitos sobre a própria realidade "como se fossem determinantes históricas, esmagadoras, em face das quais não lhes cabe outra alternativa, senão adaptar-se" (Freire, 1987, p. 53). 


\section{Procedimentos Metodológicos}

A presente pesquisa foi realizada no bairro Iguape, no município de Ilhéus-BA, nas imediações da Escola Padre Giuseppe Bonomi, durante o período de março a novembro de 2018, no contexto de um curso de formação de professores, em colaboração com as professoras da escola e o Grupo de Estudos sobre Abordagem Temática no Ensino de Ciências (GEATEC) $)^{2}$, denominado "O Brincar no contexto dos Três Momentos Pedagógicos", com carga horária de 40 horas, e contou com a participação de 8 (oito) professoras da referida escola, bem como envolveu diversos moradores da comunidade do bairro. A Escola Padre Giuseppe Bonomi é uma instituição de cunho filantrópico, mantida por recursos obtidos de doações e parcerias com empresas da iniciativa privada e instituições religiosas. A escola está localizada em uma área litorânea, banhada pelo Rio Almada que passa em meio à comunidade. Às margens desse rio, encontra-se uma grande área de manguezal, em que muitos moradores desenvolvem atividades pesqueiras, sendo para a maioria uma forma de subsistência.

Em busca de alternativas para a compreensão e superação das problemáticas do bairro Iguape, a exemplo do despejo dos dejetos domésticos da escola no mangue, foi construída em coletivo uma Fossa Séptica Ecológica, seguindo os fundamentos da TS, que envolveu duas etapas, cada qual, sistematizada com base nos $3 \mathrm{MP}$, quais sejam:

i) Reunião Geral: realizou-se uma reunião com os moradores da comunidade local, pais das crianças, professoras, coordenadores da escola e integrantes do GEATEC, em que foram discutidos os principais problemas do bairro, identificados no estudo de Assunção (2019), além disso, discutiu-se sobre possíveis alternativas para superá-los, por meio da TS, as quais foram sistematizadas no topo da Rede Temática (Figura 1). Essa Reunião Geral teve duração de 4 (quatro) horas e contou com aproximadamente 20 (vinte) pais e moradores.

Dentre as principais demandas da comunidade, os moradores sinalizaram que o despejo de dejetos domésticos no manguezal é uma das problemáticas mais urgentes a serem superadas na localidade. Diante disso, optou-se em implementar a TS "Fossa Séptica Ecológica", explicando o mecanismo dessa tecnologia, inclusive o processo de construção, funcionalidade e reaplicação. Os moradores consideraram importante realizar a implementação dessa TS na Escola Padre Giuseppe Bonomi, uma vez que seus dejetos domésticos são todos despejados no mangue, incluindo os dos sanitários. Nesta reunião, também discutiu-se com os participantes os principais aspectos relacionados às doenças causadas pela poluição da água (rio e mar) e também do solo, bem como aspectos de prevenção de possíveis doenças infecciosas.

2 O Grupo de Estudos sobre Abordagem Temática no Ensino de Ciências (GEATEC), vinculado à Universidade Estadual de Santa Cruz, têm desenvolvido diversas atividades voltadas para a formação de professores da Educação Básica, em algumas escolas da região sul da Bahia. O grupo tem como objetivo promover processos formativos de professores, na perspectiva da Abordagem Temática Freireana (Delizoicov, Angotti, \& Pernambuco, 2011; Silva, 2004), em parceria com escolas e Secretarias Municipais e/ou Estaduais de Educação em diversos municípios da região sul da Bahia. Mais informações sobre o grupo estão disponíveis em: https://geatecuesc8.wixsite.com/geatec 
ii) Implementação da Fossa Séptica Ecológica na escola: a construção da fossa foi realizada no feriado do dia 15 de novembro de 2018, com a participação ativa de moradores locais - em sua maioria pais das crianças da escola -, professoras da instituição, coordenação pedagógica, direção da escola, estudantes, membros do GEATEC e alguns representantes da comunidade local, como líderes comunitários. As atividades envolveram discussões sobre o papel e a importância da TS, bem como a organização de materiais e preparação do local para a implementação da fossa na escola.

As informações da pesquisa foram obtidas por meio de videogravações e entrevista semiestruturada. As videogravações foram realizadas durante a Reunião Geral de planejamento e implementação da Fossa Séptica Ecológica, com o objetivo de obter informações mais detalhadas sobre a compreensão da realidade, as demandas sociais e da apropriação de alguns fundamentos da TS. A entrevista envolveu 8 (oito) moradores da comunidade local que participaram ativamente tanto da Reunião Geral de planejamento quanto da construção da fossa. As questões que direcionaram a entrevista estão relacionadas aos fundamentos mencionados por Roso (2017), que envolvem o desenvolvimento e a implementação de uma TS, quais sejam: autonomia, tomada de decisões, coaprendizagem e reaplicação. A entrevista foi realizada tendo como referência um roteiro de questões, como mostra a Figura 2.

\begin{tabular}{|l|l|}
\hline Questões da entrevista & $\begin{array}{l}\text { Compreensões sobre os pressupostos da TS } \\
\text { (Roso, 2017) }\end{array}$ \\
\hline $\begin{array}{l}\text { 1. O que você está achando da proposta da fossa } \\
\text { séptica sustentável? }\end{array}$ & Autonomia \\
\hline $\begin{array}{l}\text { 2. Você acredita que esta fossa pode ajudar a } \\
\text { resolver o problema do esgoto que é despejado no } \\
\text { manguezal, aqui no bairro Iguape? }\end{array}$ & $\begin{array}{l}\text { Autonomia, tomada de decisões, } \\
\text { coaprendizagem e reaplicação. }\end{array}$ \\
\hline $\begin{array}{l}\text { 3. Esta fossa pode gerar alguns benefícios para o } \\
\text { meio ambiente? Quais? }\end{array}$ & $\begin{array}{l}\text { Autonomia, tomada de decisões, } \\
\text { coaprendizagem e reaplicação. }\end{array}$ \\
\hline $\begin{array}{l}\text { 4. Quais benefícios esta fossa pode gerar para o } \\
\text { bairro? }\end{array}$ & Autonomia \\
\hline $\begin{array}{l}\text { 5. Você conseguiria fazer uma fossa desta em sua } \\
\text { casa? Explique como. }\end{array}$ & $\begin{array}{l}\text { Tomada de decisões, coaprendizagem, } \\
\text { reaplicação. }\end{array}$ \\
\hline $\begin{array}{l}\text { 6. É possível se reunir com os vizinhos para fazer } \\
\text { uma fossa desta, na sua rua? Se sim, por onde você } \\
\text { começaria? Se não, explique por quê. }\end{array}$ & $\begin{array}{l}\text { Coaprendizagem, autonomia e tomada de } \\
\text { decisões. }\end{array}$ \\
\hline $\begin{array}{l}\text { 7. O que mais lhe chamou atenção durante a } \\
\text { instalação da fossa séptica? }\end{array}$ & Autonomia e tomada de decisões. \\
\hline $\begin{array}{l}\text { 8. Para você, a Tecnologia Social pode contribuir } \\
\text { para o desenvolvimento da comunidade? Em que } \\
\text { sentido esse desenvolvimento? }\end{array}$ & $\begin{array}{l}\text { Autonomia, tomada de decisões, } \\
\text { coaprendizagem e reaplicação. }\end{array}$ \\
\hline
\end{tabular}

Figura 2. Roteiro das entrevistas realizadas para pesquisa

Para melhor compreender as informações obtidas e garantir a privacidade dos sujeitos participantes desta pesquisa, utilizou-se o sistema alfanumérico para as falas 
dos moradores obtidas nas entrevistas semiestruturadas, compreendendo as entrevistas como Me1, Me2,...Men., e as videogravações sendo Mv1, Mv2,....Mvn. Destaca-se que durante a Reunião Geral de planejamento e da entrevista semiestruturada também houve a participação de colaboradores do GEATEC, que foram identificados como PQ1, PQ2 e PQ3.

As informações obtidas dos moradores, durante a videogravação e a entrevista semiestruturada, foram analisadas por meio da Análise Textual Discursiva (Moraes, \& Galiazzi, 2011), que tem sido utilizada no Ensino de Ciências como procedimento de análise em diversos estudos. Essa dinâmica é organizada em duas etapas que foram desenvolvidas da seguinte forma: a) unidades de significado: compreendem que estratégias teórico-metodológicas desenvolvidas a partir do processo da Redução Temática, que podem ser fundamentais no processo de uma educação emancipadora. No presente estudo essas unidades foram obtidas de falas de moradores durante as videogravações da Reunião Geral de planejamento e da entrevista semiestruturada; b) categorização: consiste em categorias a priori ou a posteriori, pois elas podem ser pré-estabelecidas e ancoradas em um referencial teórico. Na presente pesquisa, as categorias foram definidas a priori com base no estudo de Roso (2017) e compreendem: i) coaprendizagem e reaplicação; ii) processos de tomada de decisões e autonomia.

\section{Apresentação e discussão dos resultados}

\section{A Reunião Geral e a escolha da TS pela comunidade}

Na Escola Padre Giuseppe Bonomi foi realizada uma Reunião Geral com alguns pais dos alunos e outros moradores da comunidade do bairro Iguape, em que foram expostos, pelos membros GEATEC, diversos problemas identificados na localidade e constatados em Assunção (2019), com o objetivo de os moradores identificarem uma demanda social mais significativa, bem como a possibilidade de discutir alguns encaminhamentos para a compreensão e superação da mesma, que seria por meio da TS. As discussões realizadas no encontro seguiram a dinâmica dos Três Momentos Pedagógicos (3MP) (Delizoicov, Angotti, \& Pernambuco, 2011), também importante para a organização de atividades extra sala de aula, a exemplo de reuniões, encontros, eventos, etc (Pernambuco, 1993), tal como apresenta-se a seguir:

a) Problematização Inicial: foram apresentadas algumas imagens de problemas do bairro, como a precarização do saneamento básico na comunidade (Figura 3) que pode ocasionar sérios problemas, como a poluição do solo, do rio e do manguezal local, devido ao despejo de dejetos domésticos, entre outros problemas apontados pela população local. 


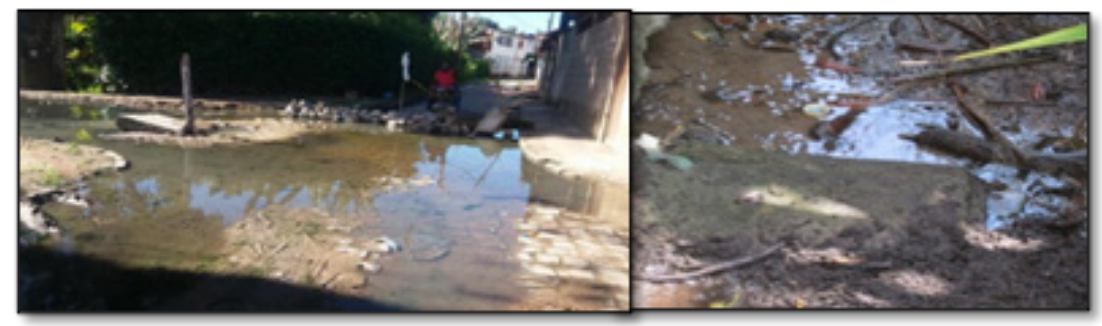

Figura 3. Imagem referente à falta de saneamento básico, em que os dejetos domésticos vão para o manguezal na comunidade do Iguape

Fonte: Autor

A apresentação das imagens da Figura 3 foram seguidas de algumas questões, tais como: $\mathrm{O}$ que as imagens representam para vocês? Vocês já viram algo semelhante? Vocês conseguem identificar esses lugares? Para onde vão esses dejetos domésticos quando chove? O que vocês acham desse esgoto sendo despejado diretamente no manguezal? Existem medidas que podem ser tomadas para solucionar essas situações? Quais? Vocês conhecem algum lugar que teve situação semelhante e que conseguiram solucionar? Como? Dentre as respostas dos moradores, destacam-se as de Mv3 e Mv2:

Com os esgotos daqui da rua beira rio, vai tudo para o mangue, contamina os animais, os caranguejos, peixes, e se a gente tiver contato, pode ainda pegar uma doença. (Mv3).

Tem uma vizinha que ficou cheia de coceira no corpo por causa da água da maré. (Mv2).

As falas dos moradores evidenciam uma preocupação acerca dos despejos irregulares de dejetos domésticos para o manguezal, devido à falta de saneamento básico na comunidade. Além disso, Mv3 e Mv2 apontam alguns problemas relacionados à saúde dos moradores locais, decorrentes do contato com os dejetos domésticos que são destinados à maré e ao rio da localidade.

Conforme Delizoicov, Angotti e Pernambuco (2011), o processo da dialogicidade não se restringe ao simples conversar entre pesquisadores, professores e educandos/ moradores do bairro sobre uma determinada questão, mas sim à apreensão mútua dos distintos conhecimentos e práticas que os sujeitos têm a respeito das situações significativas presentes em sua realidade. Dessa forma, constata-se no extrato das falas de Mv3 e Mv2 um conhecimento significativo sobre a realidade que estão inseridos, sinalizando a necessidade de uma ação que possibilite a superação dos problemas sociais vivenciados (Freire, 1987).

b) Organização do Conhecimento (OC): os colaboradores do grupo de pesquisa GEATEC discutiram com os moradores alguns aspectos relacionados aos problemas presentes na comunidade do Iguape e as consequências causadas pela falta do saneamento básico. Para isso, apresentou-se a Figura 4 com imagens de algumas situações de risco, doenças infecciosas e sintomas no organismo humano, por conta do contato direto com esses dejetos domésticos em locais impróprios. A finalidade dessa imagem foi discutir com os moradores do bairro sobre algumas doenças em decorrência da falta de 
saneamento básico, uma vez que o bairro vivencia situações semelhantes às da Figura 4.

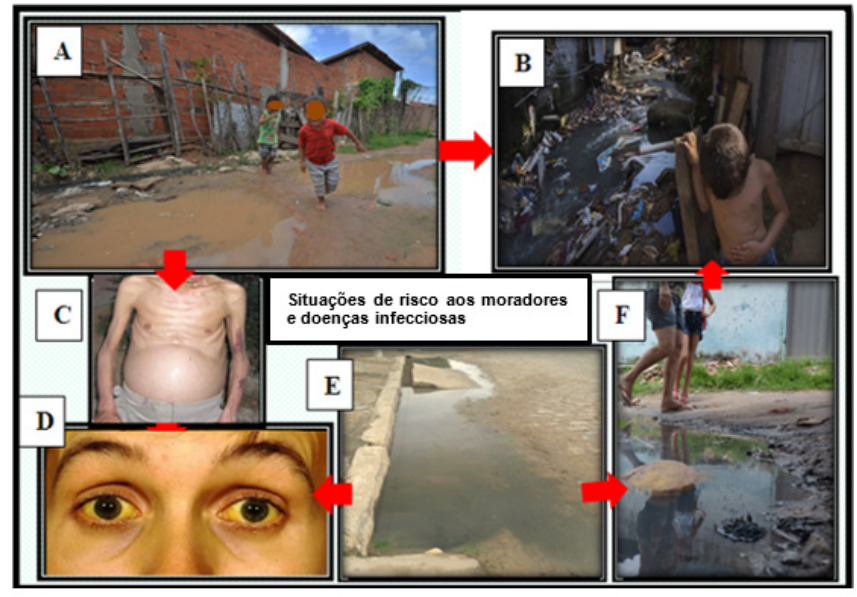

Figura 4. Representações de doenças infecciosas causadas pelo contato com o esgoto

Fonte: imagens extraídas da internet.

Com o auxílio da Figura 4, discutiu-se com os moradores diversos aspectos. Com a imagem A, abordou-se a falta de saneamento básico e o contato de crianças com os dejetos domésticos expostos na rua. Com as imagens $\mathrm{B}$ e $\mathrm{C}$, discutiu-se sobre os sintomas de doenças infecciosas, causadas por parasitoides (Amebíase, Giardíase e Teníase), devido o contato com água contaminada por dejetos domésticos, como é representada por uma criança e adolescente. Com ajuda da imagem $\mathrm{D}$, discutiu-se, também, sobre os sintomas de uma pessoa infectada por Hepatite A, que é uma doença infecciosa, transmitida pelo consumo de água e alimentos (vegetais, ostras, caranguejos etc.) contaminados com microrganismos provenientes de fezes e urina. Com as imagens E e F, discutiu-se sobre situações de riscos às doenças já citadas e, também, a outras doenças que podem ser transmitidas por estas situações, por exemplo: febre tifoide, cólera e leptospirose, que são transmitidas por microrganismos patológicos presentes nos dejetos domésticos.

Durante as discussões realizadas com os moradores sobre as consequências negativas dos dejetos domésticos que são despejados em locais indevidos, constatouse que os moradores associaram as imagens da Figura 4 à realidade em que vivem. Foi possível observar, também, que houve uma preocupação em relação aos riscos que estão expostos, uma vez que não tinham uma percepção dos problemas presentes na sua realidade, a exemplo do que é apresentado por Mv7 e Mv2.

Eu não vou comer mais marisco. Depois de saber que a gente pode pegar todas essas doenças aí, a gente corre um grande risco com esse esgoto. (Mv7).

Eu conheço um rapaz daqui da rua, que teve febre, dor de cabeça por causa que tomou banho na maré. (Mv2).

Na fala do morador Mv7, sobre as possíveis doenças infecciosas causadas pelos dejetos domésticos despejados em locais impróprios, constatou-se uma visão limitada 
com relação às contradições sociais apresentadas, pois esse morador compreende que a superação do problema local está restrita ao ato de "deixar de consumir os mariscos que são pescados na comunidade", não conseguindo compreender a totalidade do problema de forma crítica e reflexiva (Freire, 1987), e buscar outras alternativas que possibilitem a transformação local. A fala do morador Mv2 evidencia a apropriação do conhecimento relacionado às doenças discutidas e a associação entre as discussões com os pesquisadores aos problemas reais vivenciados na localidade.

Freire (1987) destaca que é necessário haver uma desnudação da realidade em que o sujeito está imerso para que possam ampliar sua visão de mundo sobre as contradições existentes em seu contexto de vida, como a falta de saneamento básico, as implicações causadas por doenças infecciosas, a contaminação do manguezal, do rio e da maré, entre outros. Segundo Delizoicov et al., (2011), as discussões sobre a realidade dos sujeitos têm em vista compreender as contradições existenciais em que estão imersos e buscar estratégias, como trabalhos colaborativos, a fim de proporcionar sua transformação, sendo as informações científicas um desses meios.

Além disso, as discussões realizadas com os moradores a partir da Figura 4 tiveram um papel fundamental no processo de legitimação da situação real em que vivem, pois contribuíram para a conscientização das possíveis doenças infecciosas causadas pelo contato com esses resíduos e as consequências desses quando destinados ao manguezal, já que uma parte significante da população local sobrevive da pesca de peixes e mariscos (Assunção, 2019).

c) Aplicação do Conhecimento: discutiu-se com os moradores possíveis alternativas capazes de solucionar as demandas da comunidade, retomando algumas questões da Problematização Inicial, e realizou-se outros questionamentos, como: existem medidas que podem ser tomadas para solucionar essas situações do bairro do Iguape? Quais? Vocês conhecem algum lugar em que há problemas semelhantes ao bairro Iguape e que foram solucionados? Como? Há possibilidade da população local cobrar do poder público e das instituições competentes uma intervenção para a melhoria do saneamento básico do bairro Iguape? Algumas respostas a essas questões podem ser ilustradas pela fala de Me6:

Rapaz, os vereadores não faz nada para melhorar essa situação... isso também é culpa deles, a pra isso que a gente bota eles lá (câmera de vereadores) [...] agente tem esperança que eles vai fazer alguma coisa pela gente, mais não adianta nada, eles desaparece. $\underline{\text { Por }}$ isso que a gente tem que se unir para fazer, aproveita agora aí, essa ideia da fossa e todo mundo se ajuntar e fazer, pra ver se melhora, senão, a gente vai viver toda vida assim. (Me6 - grifo nosso).

Durante essas discussões, os moradores apresentaram diversas alternativas para a superação da demanda local, assim como emergiu a necessidade de realizar alguma ação para amenizar e/ou evitar o despejo dos dejetos domésticos no mangue. Para isso, os integrantes do GEATEC apresentaram a alternativa da Fossa Séptica Ecológica como uma possibilidade viável para a superação do problema dos dejetos domésticos 
destinados de maneira inadequada na localidade. A fossa é um sistema em que os dejetos passam pelo processo de tratamento biológico, devido à ação das bactérias aeróbicas e anaeróbicas que são responsáveis pela eliminação da matéria orgânica e transformação da matéria inorgânica (Fezes e urinas - danosos à saúde humana e ao meio ambiente quando descartadas de modo irregular), contribuindo com o tratamento e descarte correto desses dejetos domésticos.

O grupo de pesquisa apresentou o modelo da fossa como uma TS, explicando que ela é compatível com as condições socioeconômicas da comunidade, pois essa é considerada por diversas organizações da iniciativa privada, governamentais e não governamentais como uma alternativa econômica e eficaz, capaz de contribuir significativamente na superação de demandas sociais (Lassance Jr., \& Pedreira, 2004). Com o objetivo de informar aos moradores de maneira mais detalhada a proposta da Fossa Séptica Ecológica, os integrantes do GEATEC explicaram seu mecanismo de funcionamento, a função, as características e a forma de desenvolvimento na comunidade. Também foram apresentados os materiais necessários para a sua produção, as etapas referentes à sua construção, bem como a função biológica no processo de tratamento dos dejetos, tendo em vista, analisar o envolvimento dos sujeitos participantes à luz da coaprendizagem e reaplicação, como também a tomada de decisões e a autonomia, mediante as falas e ações que constituíram as etapas pedagógicas da TS em questão.

Após as discussões sobre a viabilidade da fossa na comunidade, salienta-se que, em comum acordo, pesquisadores, professores, coordenadores e moradores decidiram construir a mesma nas imediações da Escola Padre Giuseppe Bonomi, pelo fato de identificar a necessidade dessa TS, nesse espaço escolar. A opção pelo local da escola se deu pelo fato da mesma descartar de forma irregular seus dejetos domésticos no manguezal, além de ser um espaço acessível à comunidade. Nesse sentido, todos os participantes acordaram que a escola seria o local propício para a construção modelo desta TS, pois os demais moradores poderiam reaplicá-la nas suas respectivas residências.

Decidiu-se, em conjunto com os pesquisadores e moradores, o local para a instalação da fossa que foi no fundo da escola, pois este lugar tinha condições favoráveis, tanto nos aspectos físicos (espaço apropriado, declive do local, próxima à rede de esgoto que destinava os dejetos para o manguezal), quanto aos aspectos geográficos (o tipo de solo consistente, apropriado para escavação e sustentação do sistema da fossa).

Os moradores realizaram a escavação do solo com as seguintes dimensões: 1,5 metros de profundidade; 2,5 metros de comprimentos e 0,80 metros de largura para que pudessem colocar os tambores enterrados no solo. Após a escavação, constatou-se que havia água minando do solo, em função da proximidade com o manguezal. Para solucionar esta situação a equipe retirou a água com baldes plásticos e realizou uma contenção para garantir a instalação da fossa de forma segura.

Quanto à instalação hidráulica do sistema da fossa, conectaram-se os tubos e seus acessórios de PVC nos três tambores. Os moradores, com a ajuda dos especialistas introduziram pedaços de bambus no terceiro tambor para a fixação das bactérias 
anaeróbicas, responsáveis pela deterioração dos dejetos. A Figura 5 ilustra o procedimento da montagem do sistema hidráulico da fossa realizado na escola.
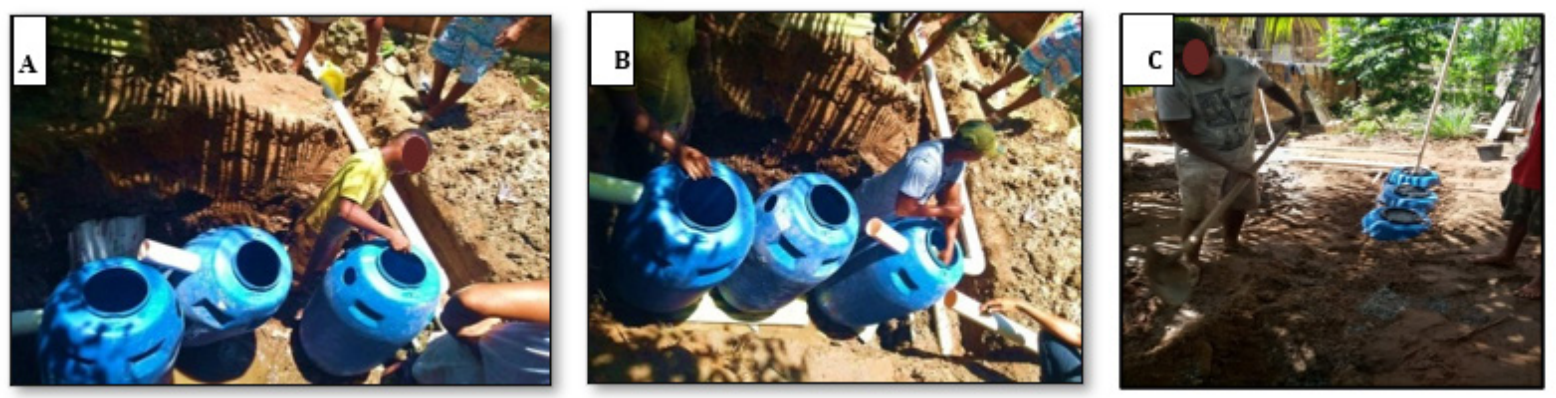

Figura 5. Participação dos moradores na construção da Fossa Séptica Ecológica na comunidade

Fonte: Autor

Após a montagem do sistema hidráulico, como ilustra a Figura 5 (A e B), preencheu-se com terra os espaços entre os tambores (Figura $5 \mathrm{C}$ ), pois é importante que o local esteja completamente preenchido com um material adequado para garantir o funcionamento correto no sistema da fossa. Também foi construído um sumidouro que consiste em uma vala, no qual colocou-se brita e areia para ajudar a filtrar as pequenas partículas dos dejetos que restaram no processo de tratamento, evitando a contaminação do solo.

Durante todas as atividades de construção e instalação da fossa, os moradores participaram ativamente, com sugestões sobre aspectos que envolveram a instalação hidráulica da fossa, o tipo de solo, medidas preventivas em relação ao funcionamento da fossa, tais como: a introdução de entulhos, nivelamento dos tambores, nivelamento do sistema hidráulico, contenção para evitar a infiltração de água, etc. Além disso, os moradores participaram na organização dos materiais para construção da fossa: reposição de materiais (entulhos, terras, bambus etc.), reposição das ferramentas nos lugares corretos, entre outras. Aqui, também, é importante destacar a participação ativa das mulheres durante as atividades, uma vez que estas contribuíram significativamente em todas as atividades, como ilustra a Figura 6.
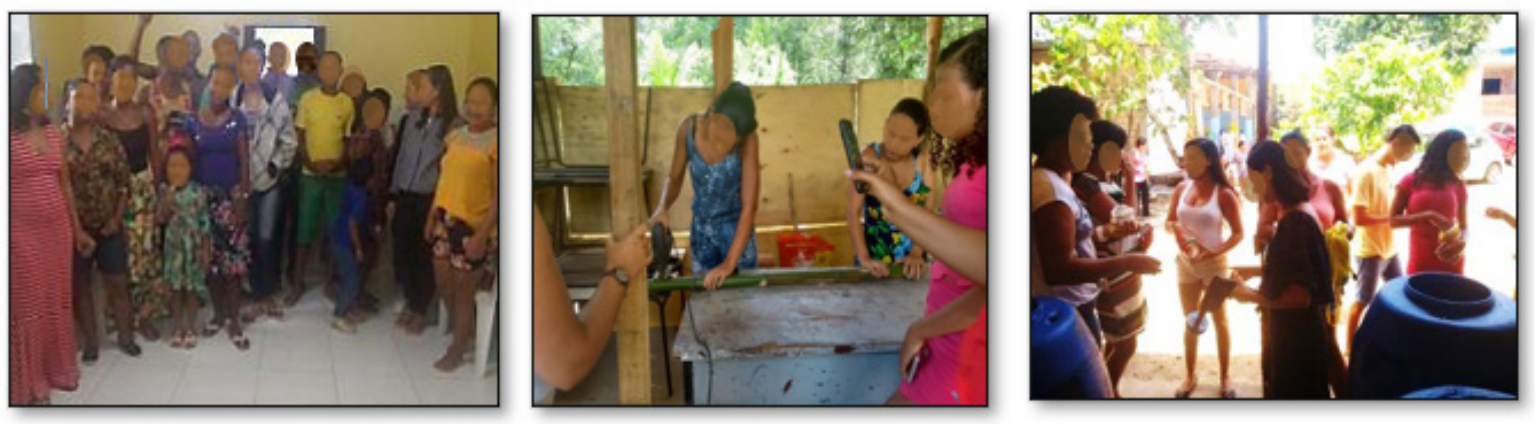

Figura 6. A participação da comunidade do Iguape nas etapas da construção da Fossa Séptica Ecológica

Fonte: Autor 
Uma análise mais detalhada do envolvimento dos moradores durante a construção da Fossa Séptica Ecológica, em especial, quanto às questões que envolvem a autonomia, tomada de decisões, coaprendizagem e a reaplicação, será apresentada no próximo tópico.

\section{Aspectos da Tecnologia Social na comunidade do Iguape e sua relação com o Ensino de Ciências}

\section{Coaprendizagem e Reaplicação}

O modelo de desenvolvimento tecnológico na perspectiva da TS baseia-se na solução de problemas locais, tendo em vista a participação efetiva da comunidade local, a fim de propiciar um novo cenário de democratização do saber e desenvolver de forma colaborativa estratégias para inclusão social, no sentido de promover a qualidade de vida da população local. Nesse sentido, vale destacar as falas de alguns moradores que participaram do processo de seleção e implementação da fossa, a exemplo dos moradores Mv7 e Mv8:

Pelo que vi e aprendi aqui hoje, eu consigo fazer (a fossa) lá com os meus primos e vizinhos de lá do São José. (Mv7- grifo nosso).

Outra coisa também é ver que o povo unido pode mudar muita coisa e isso mostra que a gente pode mudar nossa rua, pode acabar com esse esgoto da rua, porque agora, vimos que a gente tem força, é só saber usar. (Mv7- grifo nosso).

O que eu estou impressionado aqui, é que o povo veio e estão participando para aprender e fazer depois em suas casas e não precisar pagar caro, principalmente, a mão-de-obra e cimento, que é o que pesa no bolso (Mv8 - grifo nosso).

$\mathrm{Na}$ fala do morador Mv7 há indicativos que se aproximam da perspectiva coaprendizagem, uma vez que ele está participando do processo de implementação da fossa e por meio dessa interação relata que foi possível aprender como fazer, além de explicar seu interesse em reaplicá-la em outra localidade. Roso (2017) explicita que a coaprendizagem contribui na formação dos seus atores sociais para o "saber fazer" e que os conhecimentos e as práticas desse processo possam ser compartilhados no sentido de promover a solução para o local, pensada para o contexto em que é demandada, a partir da aquisição de novos conhecimentos.

No extrato das falas de Mv7 e Mv8 percebe-se que houve uma apropriação dos fundamentos da TS, bem como uma visão crítica da realidade, tornando-se um elemento fundamental para construção mútua dos conhecimentos envolvidos, ou seja, a efetivação da coaprendizagem (Roso, 2017) no processo formativo/educativo que poderá potencializar a reaplicação da tecnologia na comunidade e contribuir para a superação da demanda social local. Essa discussão explicitada sobre os sujeitos Mv7 e Mv8 está em sintonia com os pressupostos teóricos de Freire (1987), ao apontar que só é 
possível aprender verdadeiramente, aquele que se apropria do 'aprendido', transformando em empreendido para que possa aplicar os conhecimentos adquiridos em situações existenciais concretas, a fim de transformá-las. Em outros termos, os moradores Mv7 e Mv8 compreendem que a ação realizada em sua localidade, possibilita a transformação da problemática local e propicia uma postura crítica e libertária, diante do seu contexto sócio-histórico.

Nesse sentido, também constatou-se nas falas dos moradores Mv7 e MV8 que os conhecimentos envolvidos no desenvolvimento de uma TS perpassam a concepção de uma reprodução de um saber técnico, bem como potencializam uma aprendizagem mútua entre os seus participantes, pois o aprendizado se dá de forma homogênea, respeitando o lugar de fala e saberes de todos os sujeitos, propiciando assim, um pensamento crítico transformador, que se se aproximam da coaprendizagem (Roso, 2017).

Os moradores Mv8 e Mv7 também sinalizaram as ações coletivas a serem desenvolvidas na reaplicação da Fossa Séptica Ecológica:

Eu acho boa. Boa mesmo, vai ajudar a não poluir o mangue. Pensei que era mais difícil de fazer, mais vejo que dar pra fazer, é só os moradores querer, eu posso ensinar o que aprendi aqui. (Mv8 - grifo nosso).

A gente tem que começar a fazer a nossa parte. Toda vez é assim, vêm aqui promete que vai consertar as ruas e o esgoto e depois some, desaparece, esquece da gente e o esgoto continua aí a céu aberto, a rua esburacada. A gente precisa se unir, não dar mais para ficar assim não. (Me3- grifo nosso).

Destaca-se na fala do morador Mv8 aspectos que contemplam a coaprendizagem, em especial, quando o mesmo menciona que aprendeu o processo de construção da fossa e pretende efetivar a sua reaplicação na comunidade local por meio de uma ação colaborativa, que é fundamental para a apropriação dos conhecimentos na construção de uma TS, semelhante o que é abordado por (Lassance Jr., \& Pedreira, 2004). Outro fator relevante na fala de Mv8 está no fato do morador explicitar que pode "ensinar o que aprendeu" - caracterizando apropriação dos conhecimentos relacionados à fossa, convergindo assim, aos fundamentos que constituem a TS, como é explicitado por Roso (2017), bem como a coaprendizagem e autonomia, viabilizando a sua reaplicação. Para Dagnino (2015), a TS ao ser reaplicada pelos atores sociais tem o propósito de superar as demandas sociais que permeiam o seu contexto sócio-histórico. Para tanto, é necessário que a práxis da TS seja efetivada em uma perspectiva interdisciplinar, dialógica, colaborativa e societária (Lassance Jr., \& Pedreira, 2004).

A importância da ação colaborativa no desenvolvimento da Fossa Séptica Ecológica também é apresentada pelo morador Mv7 ao afirmar que "o povo unido pode mudar muita coisa e isso mostra que a gente pode mudar nossa rua" (grifo nosso). Isso sinaliza que a TS pode subsidiar a população local para uma transformação socioeconômica e socioambiental, tendo em vista reduzir possibilidades de transferência ou importação de tecnologias na perspectiva do sistema hegemônico, (Dagnino, Bagattolli, \& Kate, 
2009). Nesse sentido, uma proposta crítico-transformadora balizada nos fundamentos da TS busca opor-se a um sistema hegemônico e promover a democratização do saber, tornando-se fundamental para construção crítica dos sujeitos participantes, bem como a compreensão e superação das demandas sociais locais (Roso, 2017).

Qualquer proposta para fins pedagógicos ou tecnológicos que não respeita e nem leva em consideração as especificidades locais caracteriza-se como uma invasão cultural, segundo Freire (1987), em que reduzem-se a um processo opressor, tendo em vista meros objetivos de suas ações, tornando-os manipuláveis, passíveis e alienados. Contrapondo esse processo, a TS tem em vista o desenvolvimento local, pois integra as ações/iniciativas inovadoras e mobilizadoras, como é possível constatar na fala do morador Mv6, em especial, quando ele fala:

Por isso que a gente tem que se unir para fazer, aproveita agora aí, essa ideia da fossa e todo mundo se ajuntar e fazer, pra ver se melhora, senão, a gente vai viver toda vida assim. (Me6 - grifo nosso).

O morador Me6 sinaliza a ação colaborativa como uma forma de enfrentamento dos problemas imersos na sua realidade, o que indica uma dimensão crítica do conhecimento para compreensão e transformação da sua realidade (Auler, \& Delizoicov, 2015). Nesse sentido, a fala de Me6 faz referência à união e o empenho da comunidade como um recurso de suma importância para a sua transformação, o que está em sintonia com os fundamentos da TS, pelo fato da mesma articular as potencialidades dos participantes locais com as condições e recursos disponíveis (Lassance Jr., \& Pedreira, 2004). Além disso, as propostas colaborativas direcionadas pela TS, como são apresentadas na fala de Me6, buscam o empoderamento e autogestão de seus usuários, possibilitando-os assumir papéis diferentes do convencional, como uma espécie de técnico que também educa ao se educar, ou seja, uma construção mútua dos conhecimentos, o que está em coerência com a coaprendizagem (Roso, 2017).

O morador Me6 aponta o trabalho colaborativo como um recurso essencial para formação crítica do sujeito, bem como para a transformação do seu contexto social. Para Freire (1983), a educação desempenha um papel fundamental para a humanização do homem, em que se faz necessário uma ação consciente no sentido de transformar o mundo, e as transformações podem ocorrer por meio de ações colaborativas, como também por interação social, como é explicitado na fala de Me6. Destaca-se que a dialogicidade, a problematização e conscientização são imprescindíveis na efetivação de trabalhos colaborativos, propiciando a construção do sujeito crítico e a transformação permanente da sua realidade (Roso, 2017).

Tendo como horizonte o processo de formação de sujeitos crítico-transformadores, a fim de possibilitar as transformações culturais e sociais/socioambientais, vale destacar o diálogo entre o pesquisador PQ1 e os moradores M8 e M2:

O que mais lhe chamou a atenção durante a instalação da fossa séptica? (PQ1).

$\mathrm{Na}$ hora de cortar e furar as bombonas foi bem interessante. Todo mundo participou, as 
mulheres ajudou bastante também, e olhando que a gente aprende a fazer. Porque não é tão difícil como imaginava, quando você falou em tecnologia imaginei outra coisa, mas agora eu sei que tecnologia pode ser uma coisa que a gente pode fazer também. Qualquer um aqui pode fazer em sua casa (Fossa). (Mv8 - grifo nosso).

$\mathrm{Na}$ do cano. Eu aprendi que o processo do cano ali, que entra o ar para as bactérias que ajuda a tratar o esgoto é uma coisa interessante e a gente nem sabe. E também todo o tratamento é interessante como o das bactérias aeróbicas. (Mv2 - grifo nosso).

Ao afirmar que todos participaram de forma efetiva o morador Mv8 representa uma ação colaborativa. A participação ativa do sujeito na perspectiva da TS, possibilita uma formação coletiva e transformadora, capaz de proporcionar o aprendizado mútuo, a autonomia e promovê-los em agentes transformadores da sua realidade. Diante disso, na fala de Mv2 é possível constatar a relevância da TS para a ampliação de visão de mundo, quando o sujeito explicita que aprendeu o processo biológico que ocorre na Fossa Séptica Ecológica, evidenciando que o mesmo, não foi apenas um espectador do processo, mas sim, um sujeito atuante, que por meio dessa ação colaborativa adquiriu conhecimentos significativos para o seu contexto sócio-histórico.

O diálogo entre pesquisador e morador tornou-se fundamental para a construção do conhecimento crítico, como prática da liberdade em que a problematização parte da realidade do morador, ou seja, de situações que este, ao vivenciar, oportunizam-no a expor sua concepção a respeito da sua realidade. O morador Mv8 ao ser questionado sobre a fossa apresenta indicativos que se aproximam dos aspectos que constituem a coaprendizagem, ao enfatizar sua participação e a dos demais moradores durante todo o processo de construção da TS. Vale lembrar que coaprendizagem constitui-se como uma estratégia em que os atores sociais participam de forma efetiva em todas as suas etapas (Samagaia, 2016).

Além disso, o morador Mv8 sinaliza que a partir dessa interação adquiriram novos conhecimentos (científicos/técnicos), os quais possibilitarão a sua reaplicação, como é explicitado por Dagnino et al. (2004). Tendo em vista que a coaprendizagem se constitui no processo de interação entre o conhecimento popular e o científico, mediante o desenvolvimento de uma TS, uma vez que o sujeito se aproprie desse conhecimento, torna-se fundamental para o desenvolvimento da sua autonomia, contribuindo de forma significativa para reaplicar essa TS no seu contexto social. Portanto, faz-se necessário que os sujeitos trabalhem em conjunto na construção de uma TS, levando em consideração as adequações sociotécnicas, a fim de superar uma demanda social e propiciar a transformação local (Samagaia, 2016).

É perceptível na fala de Mv8 a superação das contradições sociais que estão presentes em seu cotidiano, por meio do trabalho colaborativo. Há, também, evidências que a compreensão do morador Mv8 transcende o nível de consciência real afetiva, para o nível de consciência máxima possível, como é discutido por Freire (1987), uma vez que ele concebe a Fossa Séptica Ecológica como uma possibilidade de superação das demandas sociais, por meio de um pensamento crítico que viabiliza soluções, antes não 
percebidas pelos sujeitos participantes. Outro aspecto coerente com os fundamentos da TS, é a coaprendizagem que pode ser constatado na fala de Mv8, refere-se ao fato de ele mencionar todos os moradores como participantes de mesma magnitude e contribuintes do processo, não só no desenvolvimento da TS, mas de uma reflexão fundamentalmente coletiva. A coaprendizagem é compreendida por Samagaia (2016) como uma aprendizagem mútua, constituída a partir da interação de diferentes conhecimentos sobre uma proposta societária, além disso, nesse processo, os sujeitos não são passivos, mas sim, atuantes em todas as etapas de desenvolvimento da TS.

Já na fala de Mv2 é possível identificar a apropriação do conhecimento científico envolvido no processo biológico da fossa, o que poderá ampliar sua visão sobre diversos fatores presentes na TS em questão, bem como contribuirá para a desconstrução do senso comum sobre a ação dos microrganismos presentes em matérias orgânicas que fazem parte do seu cotidiano. Nesse sentido, a apropriação do conhecimento científico poderá contribuir tanto para uma visão crítica sobre o meio em que vive quanto para proporcionar uma qualidade de vida ao sujeito, uma vez que a apreensão de novos conhecimentos científicos possibilitará novos hábitos de higiene e alimentar (Freire, 1987). Essa apropriação do conhecimento científico é compreendida por Dagnino et al. (2004) como uma construção coletiva e interdisciplinar, tornando-se fundamental para a compreensão que as demandas sociais presentes em uma comunidade sejam pensadas para além dos limites técnicos.

A compreensão de Mv2 sobre o processo da fossa indica que ele pode se tornar agente transformador da sua realidade, contribuindo para o enfrentamento dos problemas locais. Conforme já explicitado, essa concepção converge com os pressupostos educacionais freireanos e com alguns aspectos que abordam a coaprendizagem. Sendo assim, há indícios que a Fossa Séptica Ecológica, na perspectiva da TS, é concebida, não como uma extensão educativa, mas como uma prática de liberdade (Freire, 1983), que propicia um conhecimento crítico, o qual se constitui nas relações homemmundo, ou seja, relações de transformação que são potencializadas na problematização crítica destas relações. Para tal, compreende-se que problematizar a realidade local do sujeito, como PQ1 fez aos moradores Mv8 e Mv2, pode contribuir para superação das contradições sociais, demandando uma interação entre várias áreas do conhecimento a serem superadas, seja operacional/hidráulica, conforme explicitado por Mv8 - com relação à Fossa -, ou biológico, conforme mencionado por Mv2.

Ainda, no processo de implementação da atividade, outros questionamentos foram realizados aos moradores participantes, dentre eles destaca-se a interação entre PQ1 e Me1, a saber:

A senhora conseguiria fazer uma fossa desta em sua casa? (PQ1).

Sim, antes nem sabia que dava para fazer uma fossa desse jeito e que poderia ajudar a gente aqui, mas agora que vi fazendo, não só vi, mas ajudei também a fazer, consigo sim, agora tá mais fácil. Vou aproveitar o final de semana e vou fazer lá em casa com meu marido. (Me1- grifo nosso). 
Pretende fazer com sua família, apenas? (PQ1).

Vou ver se consigo fazer com meus vizinhos, se eles quiser, né. É bom porque cada um aqui já aprendeu como faz (a fossa), agora é só marcar para todo mundo fazer. O negócio é o povo se unir para ajudar. (Me1).

No diálogo entre PQ1 e Me1, há indicativos de que a compreensão acerca da reaplicação da fossa aproxima-se dos aspectos que constituem a coaprendizagem, pois Me1 sinalizou que a partir da interação no desenvolvimento da TS foi possível se apropriar dos conhecimentos necessários que viabilizam a sua reaplicação na comunidade local. Além disso, a fala de Me1 evidencia uma ação participativa, coletiva e colaborativa, tendo em vista a busca por soluções para a demanda imposta pela problemática hegemônica (Roso, 2017). Nesse sentido, a atuação por parte dos moradores da comunidade poderá estabelecer uma cultura de participação social viabilizando o enfrentamento dos problemas locais, e buscando superar as demandas da sua realidade, como é constatado na fala de Me1, em que a partir da união dos moradores a TS poderá contribuir para a transformação local.

Em síntese, tendo como parâmetro o princípio da coaprendizagem, foi possível identificar nas falas dos moradores aspectos que se aproximam mais do processo de reprojetamento de forma coletiva, tanto no ponto de vista do sujeito, como em todo o processo que concebeu a TS em questão. Além disso, também identificou-se uma visão crítica e reflexiva dos moradores participantes sobre a tecnologia desenvolvida, que agregaram ao conhecimento popular novos conhecimentos científicos, possibilitando a reaplicação da TS, ou seja, a transformação sociotécnica, por meio do processo dialógico e colaborativo (Lassance Jr., \& Pedreira, 2004).

\section{Processos de tomada de decisões e autonomia}

O bairro Iguape apresenta sérios problemas atrelados à falta de saneamento básico, cujo destino dos dejetos domésticos produzidos nas residências é o manguezal que cerca a localidade. Para tanto, há uma reivindicação, insatisfação e indignação por parte dos moradores sobre a problemática (Assunção, 2019). Por exemplo, o morador Mv6 reconhece a falta de saneamento básico na comunidade que associa à poluição do manguezal:

A fossa vai ser boa chance para ajudar o mangue e também resolver o problema da gente aqui que estamos sofrendo com esse esgoto, que é um caso sério, por isso que eu vou participar de tudo que poder, para aprender e fazer uma lá em casa. Já vai ser um problema a menos para o mangue, espero que todos moradores pense assim. (Mv6).

Eu preciso da planta da fossa para levar para fazer uma lá em casa. (Mv6 - grifo nosso).

Mais pra isso todos moradores tem que se ajudar, se for assim a gente não consegue mudar essa situação. (Me2 - grifo nosso).

A partir da compreensão do morador Mv6 é possível identificar um sentimento 
de pertencimento à realidade vivenciada por ele, uma vez que aponta a fossa como uma possibilidade que permitirá superar a problemática da realidade em que vive. Nas relações tecidas pelo morador M6, entre os problemas locais e a TS em questão, também percebe-se a legitimação dos problemas que permeiam o seu contexto social, prevalecendo em suas explicações o senso comum. Porém, constata-se que em sua fala fica explicíto o interesse em compreender os conhecimentos técnico-científicos sobre o mecanismo de construção e funcionamento da fossa, pois o morador compreende que esse conhecimento lhe possibilitará a reaplicação da tecnologia em sua residência. Portanto, evidenciou-se uma aproximação da fala de Mv6 com os processos de tomada de decisões propostos por Roso (2017), pelo fato do morador apontar o sentimento de pertencimento como parte de um processo de conscientização, capaz de propiciar sua participação efetiva durante o planejamento e o desenvolvimento da TS na comunidade. Essa tomada de decisões, na compreensão do autor, pode propiciar a aquisição de novos conhecimentos (conhecimentos técnicos e científicos) de forma que contribua para a reaplicação da TS no sentido de promover a transformação da realidade em que vivem.

O morador Mv3 também explicita a importância da TS quanto às implicações sociais da realidade local, e aponta que:

A proposta (fossa séptica) é boa, por isso que eu estou filmando tudo, porque daí fica mais fácil para aprender. E depois eu vou ver com as empresas aqui do bairro para conseguir as bombonas para a gente fazer umas dez fossas aqui na rua de baixo, a rua beira riu. Pelo menos umas dez fossas dessas dá pra gente fazer. (Mv3 - grifo nosso).

Nesta fala do morador Mv3 é possível identificar que o mesmo tem interesse em compreender todos os aspectos referentes à construção e ao funcionamento da fossa, a fim de efetivar a sua reaplicação na comunidade com/para os demais moradores. Além disso, ele apresenta alternativas viáveis para a aquisição dos materiais necessários para compor a TS, como a busca de parcerias nas empresas próximas para a obtenção das "bombonas" (tambores plásticos). Isso é importante, uma vez que Dagnino (2011) chama a atenção para que a TS seja desenvolvida de forma colaborativa, em que haja uma participação efetiva e homogênea dos moradores, órgãos e instituições competentes em todo o processo do seu desenvolvimento.

Contudo, destaca-se que o morador Mv3 apresenta uma compreensão limitada acerca das possibilidades de resolução do problema local, que no caso configura-se como uma situação-limite (Freire, 1987), uma vez que ele aponta as empresas privadas como único meio para estabelecer uma parceria, não se atentando em reivindicar do poder público e de outros órgãos competentes uma posição efetiva frente aos problemas sociais presentes no bairro. A compreensão de Mv3 se restringe em buscar possíveis alternativas para atender à necessidade de uma pequena parcela da população local, em vez de uma mobilização da comunidade junto aos órgãos competentes - Poder Público e Empresa Baiana de Águas e Saneamentos (EMBASA) -, que poderia implicar em possíveis soluções que atendam a toda população local (Lassance Jr., \& Pedreira, 2004).

Em síntese, a partir das falas dos moradores Mv6 e Mv3, constatou-se que há 
uma necessidade de que esses compreendam de forma crítica as questões referentes ao saneamento básico local e também intervenham nessa problemática de forma efetiva (Freire, 1987). Não só no sentido de amenizar os impactos negativos e potencializar os aspectos positivos, durante a implementação da Fossa Séptica Ecológica na comunidade, mas compreender que os aspectos que envolvem toda a discussão (implicações sociais e alternativa de superação) devem propiciar uma participação social mais efetiva da população local, que as decisões tomadas sejam de forma unânime e proporcionem o bem estar e a qualidade de vida da comunidade como um todo (Roso, 1987). A visão limitada ou acrítica dos moradores Mv6 e Mv3, agora é substituída por um posicionamento crítico para além da solução de um determinado problema local, capaz de promover a transformação e humanização permanente do seu contexto social, aproximando-se da proposta libertadora freireana (Freire, 1987).

Observou-se nas falas dos moradores Mv7 e Me8 alguns aspectos que legitimam as contradições sociais da comunidade, bem como algumas medidas para superá-las, como explicitam:

Eu faço parte da liderança da comunidade do São José e lá não tem rede de esgoto, e achei a ideia da fossa boa e pretendo levar pra lá, para fazer com os moradores de lá do são José. Meus primos são pedreiros e eles vão gostar dessa ideia, quero até que você me dê à planta da fossa, olhando por ali a gente faz tranquilamente lá. (Mv7).

Quem precisar fazer uma fossa dessa é só me chamar que eu faço, não é difícil. Dá pra fazer e já tou pensando fazer uma lá em casa. Aprendendo mais algumas coisas aqui eu consigo fazer. A instalação já sei como fazer, aí o resto fica fácil. (Me8).

De acordo com as falas dos moradores Me7 e Me8, percebe-se que há interesses em reaplicar a Fossa Séptica Ecológica na comunidade, com o objetivo de superar o problema local. O morador Me7 enfatiza que tem interesse em reaplicar coletivamente a proposta em outra localidade, da qual ele faz parte, o que evidencia uma aproximação, estando em conformidade com Dagnino (2014) quando explicita que "ao conjunto das formas de politização alternativas que se organizam em torno de uma solidariedade coletiva de um povo" (p. 94). A fala desse morador apresenta indicativos que se alinham aos estudos discutidos por Lassance Jr. e Pedreira (2004), em que os processos de tomada de decisões na perspectiva da TS não são tradicionais ou estritamente técnicos, mas tem em vista a coletividade, agregando valores democráticos, éticos e o protagonismo social mediante o seu desenvolvimento na localidade. Compreende-se que Me7 não endossa o modelo de decisões tecnocráticas, a qual consiste em uma organização: hierarquizada, individualizada, tendo em vista o lucro e reprodução da exclusão social (Dagnino, 2014).

Quanto ao morador Me8, há indicativos de que ele está interessado em se apropriar dos conhecimentos técnicos e científicos que concernem ao desenvolvimento da fossa juntamente com os conhecimentos relacionados à construção da mesma, ou seja, a apropriação do conhecimento científico somado ao conhecimento popular preexistente (Dagnino et al., 2004; Roso, 2017), estando em coerência com o processo de tomada de 
decisões que possibilita a autonomia do sujeito participante ao explicitar o interesse em reaplicar a proposta na comunidade em uma perspectiva colaborativa. Nesse sentido, a compreensão do morador Me8 aponta para uma concepção que aproxima a iniciativa de produção colaborativa, como é discutido por Dagnino (2014) sobre a relevância do trabalho colaborativo entre os agentes sociais no decorrer do desenvolvimento de uma TS e as suas possíveis contribuições para as transformações sociais. Segundo Lassance Jr. e Pedreira (2004), a soma do conhecimento popular ao conhecimento sociotécnico proposto pela TS contribui significativamente para a sustentabilidade econômicofinanceira e propicia o desenvolvimento de empreendimentos solidários.

A fala de Me8 apresenta a postura de um sujeito atuante no enfrentamento dos problemas presentes na sua realidade, aproximando-se da tomada de decisões, uma vez que essa consiste em oportunizar a todos os sujeitos participantes nas decisões sobre o sistema da TS que está sendo implementada. Roso (2017) compreende que o processo de tomada de decisões propicia ao ator social decisões coletivas, debatidas e, então, tomadas de forma democrática, valorizando os conhecimentos populares e científicos, potencializando o protagonismo social local.

Em suma, as falas dos moradores Me7 e Me8 apresentaram indicativos de uma concepção crítica sobre a realidade em que vivem, tendo em vista a construção da Fossa Séptica Ecológica como uma potencial alternativa para superação das demandas sociais. Os processos de tomada de decisões foram evidenciados em diversas situações referentes à participação no desenvolvimento da TS. Mediante essas discussões, constatou-se que a interação dos moradores pode contribuir para a autonomia e a promoção dos sujeitos participantes na transformação social da realidade em que estão imersos. Além disso, as falas dos moradores indicam uma concepção em processo de libertação acerca da contradição em que vivem (como os problemas ligados a falta de saneamento básico), engajando-se no processo de consciência cada vez mais crítica de seu papel de sujeito na tomada de decisões a fim de transformar sua realidade.

\section{Algumas considerações e contribuições para a Educação em Ciências}

A construção da Fossa Séptica Ecológica na comunidade do Iguape possibilitou o envolvimento dos moradores em todo o processo, desde a seleção até a sua implementação. Essas atividades desenvolvidas em coletivo contribuíram para que esses moradores se apropriassem de alguns elementos que caracterizam os fundamentos da TS, como a autonomia, tomada de decisões, coaprendizagem e reaplicação. Por exemplo, indicativos da coaprendizagem estão presentes nos argumentos dos moradores sobre o papel das bactérias aeróbicas, em que eles passam a ter uma compreensão sobre os conhecimentos científicos do processo biológico da fossa, ainda que embrionária com relação ao conceito de coaprendizagem. Nesse sentido, constatou-se a integração do conhecimento popular ao científico, propiciando a autonomia dos sujeitos, bem como a tomada de decisões (Roso, 2017). Esses elementos são fundamentais para a efetivação 
de ações como a reaplicação da TS em questão, contribuindo para a compreensão e possíveis soluções para as demandas sociais.

Apesar da pesquisa apresentar indicativos dos moradores da comunidade do Iguape se apropriarem de alguns princípios da TS, constatou-se nas falas dos moradores que o saber fazer, a partir da apropriação dos conhecimentos que permeiam a TS, tornou-se mais explícito que o saber explicar. Isso ficou evidente quando os moradores relataram que se apropriaram dos conhecimentos que envolvem a construção da fossa, logo, estão aptos à sua reaplicação, mas apresentaram limitações em explicar com clareza as etapas que consistem dessa tecnologia. Diante disso, vale destacar que a participação efetiva do sujeito, principalmente o lugar de fala, durante a efetivação de uma proposta societária é um elemento fundamental para a emancipação de um ator social (Auler, \& Delizoicov, 2015).

Quanto à inserção da TS no contexto escolar e suas possíveis contribuições para a Educação em Ciências, Roso (2017) chama a atenção para a necessidade de se trabalhar aspectos da TS na escola, em especial, na organização curricular via IT. Ou seja, a partir da seleção das demandas locais da comunidade, que representam situações-limite, pode-se organizar o currículo da escola e trabalhar diversas áreas do conhecimento, a exemplo das Ciências Naturais. A organização dos currículos terá como ponto de partida essas demandas sociais para, após, selecionar-se os conteúdos, conhecimentos e ações necessárias serão implementadas via TS em sala de aula e/ou na realidade local.

As etapas de uma proposta pedagógica societária no espaço escolar (seleção de demandas, planejamentos e implementação), a partir dos fundamentos que permeiam a TS, também podem ser desenvolvidas em colaboração com a população local, tanto por meio dos seus conhecimentos populares integrados aos conhecimentos científicos quanto por meio de um direcionamento das Políticas Públicas, a fim garantir os seus direitos como cidadãos para transformar a sua realidade. Uma vez que as Políticas Públicas, na perspectiva da TS (Dagnino, 2014), têm sido contempladas em áreas como na agroecologia, que possibilita suprir as necessidades de segurança alimentar de agricultores e alimentação escolar em várias regiões do Brasil, porém não tem sido integrada como parte do processo de ensino/aprendizagem no contexto educacional. Percebe-se, entretanto, que há uma necessidade da interação entre o campo da inclusão social por meio das Políticas Públicas, da ciência e da tecnologia no contexto educacional como produção do conhecimento (Dagnino, 2014).

No contexto da Escola Padre Giuseppe Bonomi, elaborou-se o currículo da Educação Infantil a partir de diversas atividades didático-pedagógicas relacionadas a Ciências Naturais na perspectiva do brincar, abordando conteúdos voltados para as demandas sociais presentes na vida dos educandos, considerando, inclusive, atividades sobre a Fossa Séptica Ecológica (Archanjo, 2019; Barbosa, 2020) que se tratava de um problema local. Diante disso, fica evidente que a elaboração de propostas pedagógicas a partir dos fundamentos da TS poderão ser organizadas contemplando diversas áreas de conhecimentos e, também, serem balizadas por várias estratégias metodológicas em 
sala de aula, como desenhos, registro fotográfico, relato de sensações, brincadeiras, etc.

Outro aspecto a destacar é que durante o desenvolvimento ou reaplicação de uma TS, alguns conhecimentos e conteúdos que não foram elencados na organização do currículo podem ser necessários para a compreensão e/ou funcionamento do aparato tecnológico. Por exemplo, foi durante a construção da fossa, que constatou-se a necessidade de alguns conhecimentos de Ciências Naturais, como a análise da contaminação do solo e a análise do tipo de solo no local da instalação, pois o mesmo estava minando água e dificultando a colocação das bombonas. A partir disso, evidenciou-se que diversos conteúdos sobre o solo podem ser trabalhados em atividades que envolvem o Ensino de Ciências, tendo como referência a problemática local da comunidade, como: os tipos de solo local (arenoso, argiloso, humífero e calcário), permeabilidade do solo, granulação, os tipos de microrganismos que habitam no solo, minhocário, umidade do solo, etc.

É possível abordar outros conteúdos relacionados ao Ensino de Ciências a partir da construção da fossa, explorando aspectos como os microrganismos presentes nos dejetos domésticos, agentes decompositores, bactérias e os fungos, processos de decomposição da matéria orgânica, os gases liberados nesse processo de decomposição. Essa diversidade de conteúdos e conhecimentos científicos sinaliza um potencial na elaboração do currículo para a Educação em Ciências em diversos níveis de ensino da Educação Básica (Educação Infantil, Ensino Fundamental e Ensino Médio). O currículo escolar elaborado a partir das vivências do educando contribui para o desvelamento do seu pensamento crítico e pode auxiliar na compreensão e superação das situaçõeslimites presentes em seu contexto social (Silva, 2004). Em suma, defende-se que trabalhar na perspectiva da TS, no contexto da Educação em Ciências, poderá promover a apropriação de conhecimentos científicos bem como contribuir para a formação de um sujeito crítico capaz de enfrentar os problemas sociais, além de conscientizálos a respeitar o meio ambiente que está inserido e colaborar para a sustentabilidade socioambiental da realidade local, nacional e global. Os fundamentos da TS podem potencializar a formação do sujeito autônomo, bem como um agente multiplicador do saber (coaprendizagem) e também um agente transformador da sua realidade (Dagnino, 2011).

A presente pesquisa busca complementar os estudos de Roso (2017), Samagaia (2016), Auler e Delizoicov (2015), Dagnino (2015; 2014; 2011), Dagnino et al. (2004) e Lassance Jr. e Pedreira (2004), considerando dois aspectos: i) a inserção da TS na comunidade escolar: a escola é um ambiente acessível à população e propor atividades pedagógicas na perspectiva da TS é proporcionar a esta comunidade um espaço de discussões sobre a sua realidade, possibilitando a conscientização dos seus educandos e familiares com relação aos problemas sociais e contribuindo para a formação de atores sociais; ii) a inserção da TS na programação curricular: como possibilidade para elaborar um currículo crítico-transformador para o Ensino de Ciências, que tenha como ponto de partida as demandas sociais locais e a integração dos conhecimentos populares e científicos, a fim de promover uma formação que possibilite discutir, conscientizar e 
superar a realidade investigada, bem como promover o protagonismo social local.

Conforme já destacado, alguns estudos têm discutido a reestruturação do currículo de Ciências Naturais na Educação Básica tendo como referência a Abordagem Temática Freireana, explicitando a cultura de participação da comunidade, a exemplo de Milli, Almeida e Gehlen (2018) e Centa e Muenchen (2016). Esses estudos podem até apresentar discussões que se aproximam de alguns aspectos da TS, ao realizarem atividades didático-pedagógicas envolvendo a comunidade escolar na tentativa da superação da cultura do silêncio. Porém, eles não explicitam os Princípios (autonomia e tomada de decisões) e as Ações (coaprendizagem e reaplicação) da TS. Roso (2017) chama atenção que estudos na perspectiva da Abordagem Temática Freireana não têm abordado a inserção da TS no contexto da Educação em Ciências. Isso mostra que é importante aprofundar as discussões sobre os fundamentos que constituem a TS e sua relação com a Investigação Temática no contexto da Educação em Ciências, com o objetivo de promover o desenvolvimento dos processos educativos/formativos para a produção científica-tecnológica local, de forma dialógica e emancipadora, a exemplo das atividades desenvolvidas na comunidade escolar.

Por fim, é necessário ampliar as investigações que envolvem a TS na escola, uma vez que na presente pesquisa também emergiram algumas questões, como: de que forma é possível aprofundar a relação entre a IT e a TS no sentido de promover uma Educação em Ciências emancipadora? Como elaborar atividades de sala de aula, para o Ensino de Ciências na Educação Básica, a partir dos Princípios e Ações da TS? E, como desenvolver a formação permanente de professores para que esses possam identificar demandas sociais, proporcionar a colaboração da população local e desenvolver atividades de sala de aula? Essas questões podem direcionar o desenvolvimento de trabalhos futuros em busca de uma maior inserção da TS no contexto educacional e promover a valorização da cultura de participação, a integração de conhecimentos científicos e populares e a materialização de um produto científico-tecnológico.

\section{Agradecimentos}

Os autores agradecem ao Conselho Nacional de Desenvolvimento Científico e Tecnológico $(\mathrm{CNPq})$ pelo apoio financeiro.

\section{Referências}

Archanjo, M. G. J. (2019). Tecnologia Social no contexto de uma comunidade escolar: limites e possiblidades para a Educação em Ciências. (Mestrado em Educação em Ciências) - Universidade Estadual de Santa Cruz, Ilhéus, Bahia.

Assunção, J. L. (2019). A Abordagem Temática Freireana na elaboração de um Projeto Político-Pedagógico configurado como práxis criadora. (Mestrado em Educação em Ciências) - Universidade Estadual de Santa Cruz, Ilhéus, Bahia. 
Auler, D. (2018). Cuidado! Um Cavalo Viciado Tende a Voltar para o Mesmo Lugar. 1. ed. Appris.

Auler, D., \& Delizoicov, D. (2015). Investigação de temas CTS no contexto do Pensamento Latino-Americano. Linhas Críticas, Brasília, 21(45), 275-296.

Barbosa, L. S. (2020). O Brincar no Contexto dos Três Momentos Pedagógicos: limites e possibilidades para Educação Infantil. (Mestrado em Educação em Ciências) Universidade Estadual de Santa Cruz, Ilhéus, Bahia.

Centa, F. G., \& Muenchen, C. (2016). O Despertar para uma cultura de participação no trabalho com um Tema Gerador. Alexandria - Revista de Educação em Ciência e Tecnologia. 9(1), p. 263-291.

Costa, A. B. (2013). Tecnologia Social e Políticas Públicas. 1. ed. Instituto Pólis.

Dagnino, R., Brandão, F. C., \& Novaes, H. T. (2004). Sobre o Marco Analítico-Conceitual da Tecnologia Social: uma estratégia para o desenvolvimento. 2. ed. Komedi.

Dagnino, R., Bagattolli. C., \& Kate D. R. (2009). Tecnologia Social: ferramenta para construir outra sociedade. 1. Ed. Campinas: Unicamp.

Dagnino, R. (2011). Tecnologia Social: base conceitual. Revista do Observatório do Movimento pela Tecnologia Social da América Latina. 1(1)

Dagnino, R. (2014). Tecnologia Social: contribuições conceituais e metodológicas. Campina Grande, PB: Eduepb. Florianópolis.

Dagnino, R. (2015). Como é a universidade de que o Brasil precisa? Avaliação, 20(2), p. 293-333.

Delizoicov, D. (1991). Conhecimento, tensões e transições. Tese (Doutorado em Educação). Faculdade de Educação da Universidade de São Paulo (FEUSP), São Paulo.

Delizoicov, D., Angotti, J. A., \& Pernambuco, M. M. (2011). Ensino de Ciências: Fundamentos e Métodos. 5. ed. Cortez.

Freire, P. (1983). Extensão ou Comunicação? 7. ed. Paz e Terra.

Freire, P. (1987). Pedagogia do Oprimido. 17. ed. Paz e Terra.

Lassance, A. E. JR., \& Pedreira, J. S. (2004). Tecnologias Sociais e Políticas Públicas. 1. ed. Sorocaba: Impresso Brasil.

Marques, E. G. (2010). Educação ambientale Tecnologia Social: Juntas por desenvolvimento rural Sustentável. (Dissertação de Mestrado). Universidade Federal de Santa Maria. Santa Maria.

Milli, J. C. L., Almeida, E. S., \& Gehlen, S. T. (2018). A Rede Temática e o Ciclo Temático na busca pela Cultura de Participação na Educação CTS. Alexandria - Revista de Educação em Ciência e Tecnologia. 11(1), 71-100. https://doi.org/10.5007/19825153.2018v11n1p71 
Moraes, R., \& Galiazzi, M.C. (2011). Análise Textual Discursiva. 2 ed. UNIJUÍ.

Pernambuco, M. M. C. (1993). Significações e realidade: conhecimento. In Ousadia no diálogo - Interdisciplinaridade na escola pública. Pontuschka, N. (org.). Edições Loyola.

Roso, C. C. (2017). Transformações na Educação CTS: uma proposta a partir do conceito de Tecnologia Social. (Tese de doutorado). Universidade Federal de Santa Catarina, Florianópolis - SC.

Samagaia, R. R. (2016). Comunicação, divulgação e educação científica: Uma análise em função dos modelos teóricos e pedagógicos. (Tese de Doutorado). Universidade Federal Santa Catarina, Florianópolis- SC.

Silva, A. F. G. (2004). A construção do currículo na perspectiva popular crítica: das falas significativas às práticas contextualizadas. Tese (Doutorado em Educação). Pontifícia Universidade Católica de São Paulo, São Paulo.

Torres, J. R., Gehlen, S. T., Muenchen, C., Gonçalves, F. P., Lindemann, R. H., \& Gonçalves, F. J. F. (2008). Ressignificação curricular: contribuições da Investigação Temática e da Análise Textual Discursiva. Revista Brasileira de Pesquisa em Educação em Ciências. 8( 2), 13p. Recuperado de https://periodicos.ufmg.br/index.php/rbpec/article/view/4021

Miguel Guilhermino de Archanjo Junior

${ }^{\circ}$ https://orcid.org/0000-0003-3142-436X

Universidade Estadual de Santa Cruz Ilhéus, Bahia, Brasil miguel85archanjo@gmail.com

Simoni Tormohlen Gehlen

(1) https://orcid.org/0000-0002-9786-3392 Universidade Estadual de Santa Cruz Departamento de Ciências Exatas e Tecnológicas Programa de Pós-Graduação em Educação em Ciências e Matemática Ilhéus, Bahia, Brasil stgehlen@gmail.com

Submetido em 27 de janeiro de 2020 Aceito em 04 de maio de 2020 Publicado em 20 de maio de 2020 